\title{
Relative Quantification of Tau-related Peptides Using Guanidino-labeling Derivatization (GLaD) with Online-LC on a Hybrid Ion Trap (IT) Time-of-Flight (ToF) Mass Spectrometer
}

\author{
Jessica Z. Bereszczak and Francesco L. Brancia \\ Shimadzu Research Laboratory, Manchester, United Kingdom \\ Federico A. Rojas Quijano and Warren J. Goux \\ The University of Texas at Dallas, Richardson, Texas, USA
}

Development of a quantification method based on isotopic variants of $O$-methyl isourea (OMIU) in conjunction with reversed-phase (RP) liquid chromatography (LC) electrospray mass spectrometry is described for determining the relative quantification of $\tau$-related peptides Ac-VQIVXK-NH $\mathrm{N}_{2}$. Extracted ion chromatograms of the mass spectrometric data derived from online microcapillary LC separation identifies the retention times of the isotopically derivatized peptides together with their ion abundances. Data-dependent MSMS analysis of both derivatized variants of the same peptide provides a complementary method for identification and resolution between isobaric species. In addition, with respect to offline LC MALDI a larger number of analogues are detected and formation of amyloid is also observed for the aspartic acid and histidine-containing peptides. (J Am Soc Mass Spectrom 2007, 18, 201-207) (C) 2007 American Society for Mass Spectrometry

$\mathrm{D}$ efining cellular dynamics in terms of changes in protein expression levels means it is no longer sufficient to simply qualitatively identify proteins; instead, methods for protein quantification are required. Relative protein quantification relies largely on the use of differential stable isotope labeling [1,2]. This strategy can be achieved in vivo, by metabolic labeling of proteins by cell growth in the presence of isotopically labeled amino acids [3], or in vitro by chemical derivatization of the proteins or their corresponding proteolysis products. In both cases the proteins or peptides that are to be compared are labeled separately with isotopic variants of a specific compound. The mixtures containing isotopically derivatized peptides are then recombined before mass spectrometric (MS) analysis. Relative quantification is determined by the ratio of the ion abundances of the two derivatized peptide ions under comparison. In vivo metabolic labeling involves the growth of a given cell population in a medium containing the natural form of an essential amino acid, whereas the other cell population is grown in a medium containing the heavy isotopic variant of this amino acid, such as leucine versus

Published online October 24, 2006

Address reprint requests to Dr. Francesco Brancia, Shimadzu Research Laboratory, Wharfside, Trafford Wharf Road, Manchester, M17 1GP, UK.Email: francesco.brancia@srlab.co.uk deuterated leucine $\left(\right.$ Leu- $\left.\mathrm{d}_{3}\right)[4,5]$ or arginine versus deuterated arginine $\left({ }^{13} \mathrm{C}_{6}\right.$-Arg $)[6,7]$.

A number of methods have been developed for the selective derivatization of functional groups within proteins/peptides using isotopic variants of a given chemical reagent. The first major application of this strategy involved the derivatization of cysteine residues with isotopic variants of the ICAT, a reagent composed of an affinity tag (biotin) separated by a polyether linker from the reactive moiety $[8,9]$. Alternative postdigestion isotopic labeling techniques include selective derivatization of carboxylic acids [10] and primary amines [11-13]. However, these chemical reactions suffer from the large number of reaction sites present in the macromolecule. A far easier reaction to control is the guanidination of lysine residues based on the use of O-methyl isourea (OMIU) [14-17]. Development of a quantification method based on isotopic variants of OMIU was recently proposed in conjunction with reversed-phase (RP) liquid chromatography (LC) and matrix-assisted laser desorption ionization (MALDI) mass spectrometry (MS) [18]. This derivatization strategy, termed guanidino labeling derivatization (GLaD), has been successfully used for the relative quantification of $\tau$-related peptides using an offline LC technique combined with MALDI ToF analysis [19].

Tau is a microtubule-associated protein that controls a range of microtubule-associated functions. In Tau the formation of amyloid, an insoluble protein deposit, has 


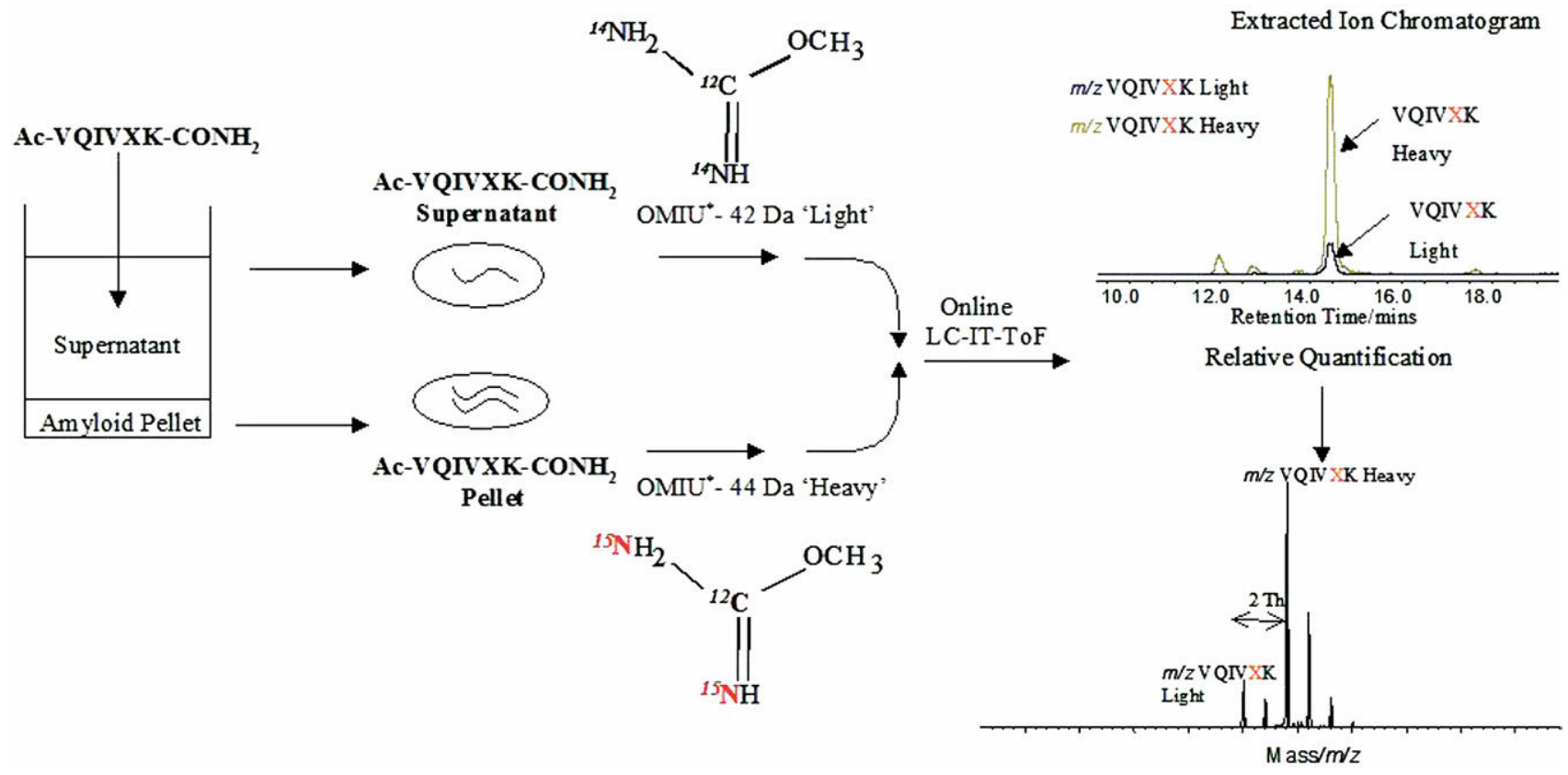

Scheme 1. Schematic illustrating the methodology used for the relative quantification of $\tau$-related mutated peptides between two different phases $(* \mathrm{OMIU}=\mathrm{O}$-methyl isourea).

been associated with Alzheimer's disease. The propensity of Tau to form amyloid has been correlated with the presence of the nucleating sequence VQIVYK. This sequence has been found to seed amyloid formation and control the rate of its formation [20]. To investigate how variations in the amino acid sequence of this nucleating peptide affect the formation of amyloid, a peptide library of Ac-VQIVXK- $\mathrm{NH}_{2}$ (X = naturally occurring L-amino acids with the exception of Cys and Leu) was generated and physical properties were measured [19]. In the MALDI-based method, relative abundances of differentially labeled peptide analogues were determined to measure the partitioning between soluble and insoluble forms in a solution containing the mixture of mutated peptides.

Here, we implement the GLaD strategy in combination with an online LC-based method coupled to a micro electrospray hybrid quadrupole ion trap (IT) time-of-flight (ToF) mass spectrometer (Scheme 1). Rapid determination of the abundance ratios together with data-dependent tandem mass spectrometric (MSMS) analysis produces a faster and more robust methodology for the relative quantification and partition coefficient determination of $\tau$-related peptides between two different phases.

\section{Experimental}

\section{Materials}

$\mathrm{N}$-Acetyl peptide amides with the sequence Ac-VQIVXK$\mathrm{NH}_{2}$, where $\mathrm{X}$ is one of 19 naturally occurring L-amino acids with the exception of cysteine and leucine, were prepared using synthetic solid-phase peptide procedures as previously described [18]. All solvents were HPLC grade and were purchased from Rathburn Chemicals
(Walkerburn, Scotland, UK). Both isotopic variants of $\mathrm{O}$-methyl isourea (OMIU) were prepared according to previously published procedures using urea $(1 \mathrm{~g}$; Fluka, Buchs SG, Switzerland) or ${ }^{15} \mathrm{~N}$-urea (1 g; Cambridge Isotope Laboratories, Andover, MA). The product identity was confirmed using ${ }^{1} \mathrm{H}-\mathrm{NMR}$.

\section{Guanidination of Lysine Residues in Peptide Mutants}

Amyloid formation was carried out by suspension of 5.3 $\mathrm{mg}$ of the mutated peptide mixture in $1.5 \mathrm{~mL} 20 \mathrm{mM}$ MOPS containing $0.01 \% \mathrm{NaN}_{3}$ at $\mathrm{pH} 7.2$ for $4-5$ days at room temperature. After centrifugation, the supernatant and pellet fractions were modified with OMIU. Lyophilized samples were dissolved in $300 \mu \mathrm{L}$ of 50:50 hexafluoro-2-propanol (HFIP): $\mathrm{H}_{2} \mathrm{O}$ and stirred for $2 \mathrm{~h}$ to allow formation of the monomeric species in solution. To the supernatant fraction $10 \mathrm{mg}$ of ${ }^{14} \mathrm{~N}-\mathrm{OMIU}$ was added and to the pellet fraction ${ }^{15} \mathrm{~N}$-OMIU was added. Diisopropylethylamine (DIEA, $50 \mu \mathrm{L}$ ) was also added to each solution and stirred overnight. Both fractions were subsequently evaporated using a nitrogen stream. The fractions were then recombined and lyophilized before LCMS analysis.

\section{Liquid Chromatography}

Reversed-phase capillary HPLC was used to separate the mixture of mutated peptides. Components of the mixture were separated using a $\mathrm{C}_{18}$ PepMap $100 \mathrm{col}-$ umn [300 $\mu \mathrm{m}$ (id) $\times 15 \mathrm{~cm}$; LC Packings, Amsterdam, The Netherlands] and a solvent gradient with mobile 

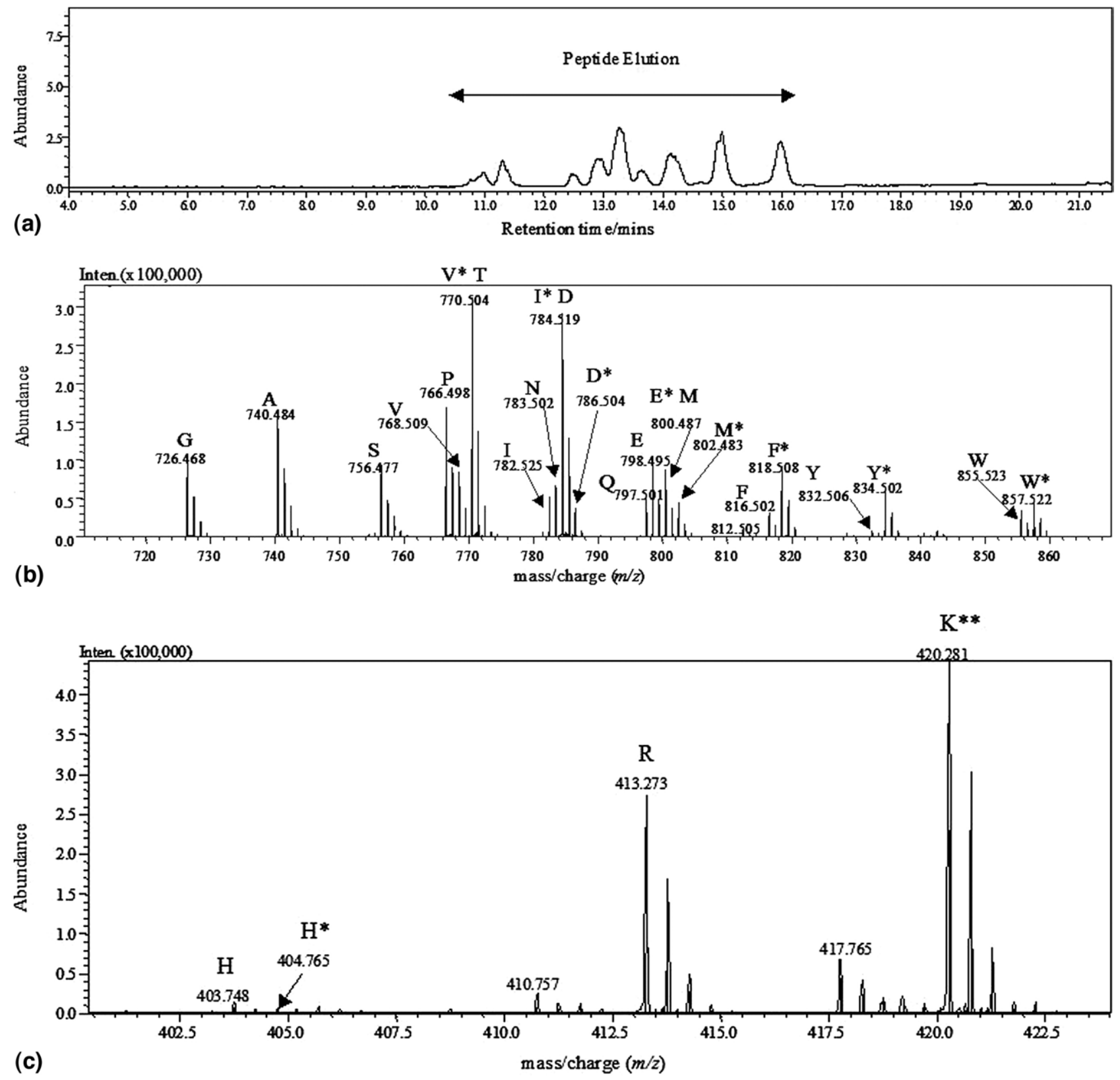

(c)

Figure 1. (a) Total ion chromatogram (TIC) for the online reversed-phase LC separation of the isotopically derivatized mutated peptide mixture. (b) Accumulated mass spectrum from 10.0 to 17.4 min identifying the presence of all singly charged isotopically derivatized mutated peptides. (c) Accumulated mass spectrum from 10.0 to 12.3 min identifying the presence of doubly charged isotopically derivatized arginine-containing and lysine-containing peptides.

phase compositions of $5 \%$ acetonitrile containing $0.1 \%$ (vol/vol) formic acid for the aqueous phase and $80 \%$ acetonitrile containing $0.1 \%$ (vol/vol) formic acid for the organic phase. LC-10AD $D_{\mathrm{VP}}$ HPLC pumps (Shimadzu Corporation, Kyoto, Japan) were used to deliver solvent at a flow rate of $100 \mu \mathrm{L} / \mathrm{min}$. A postcolumn split was used to reduce the flow to an estimated 8 $\mu \mathrm{L} / \mathrm{min}$. The composition of B was increased linearly for 20 to $22 \mathrm{~min}$ from 0 to $40 \%$. The sample was loaded into a $5 \mu \mathrm{L}$ injection loop using a six-port rheodyne valve (VICI Valco Instruments Co., Houston, TX).

\section{Mass Spectrometry}

All MS data were acquired on the LCMS-IT-ToF (Shimadzu). Electrosprayed ions were generated using a capillary voltage of $4.66 \mathrm{kV}$. A curved desolvation line (CDL) held at a temperature of $230^{\circ} \mathrm{C}$ was used to aid desolvation. Nitrogen was pumped into the ion source at a rate of $1.5 \mathrm{~L} / \mathrm{min}$ to help nebulization of the electrospray solution. A heat block temperature of $250^{\circ} \mathrm{C}$ was also used. Ions are extracted from the ion source and subsequently focused by the Q-array device, before axial injection into 

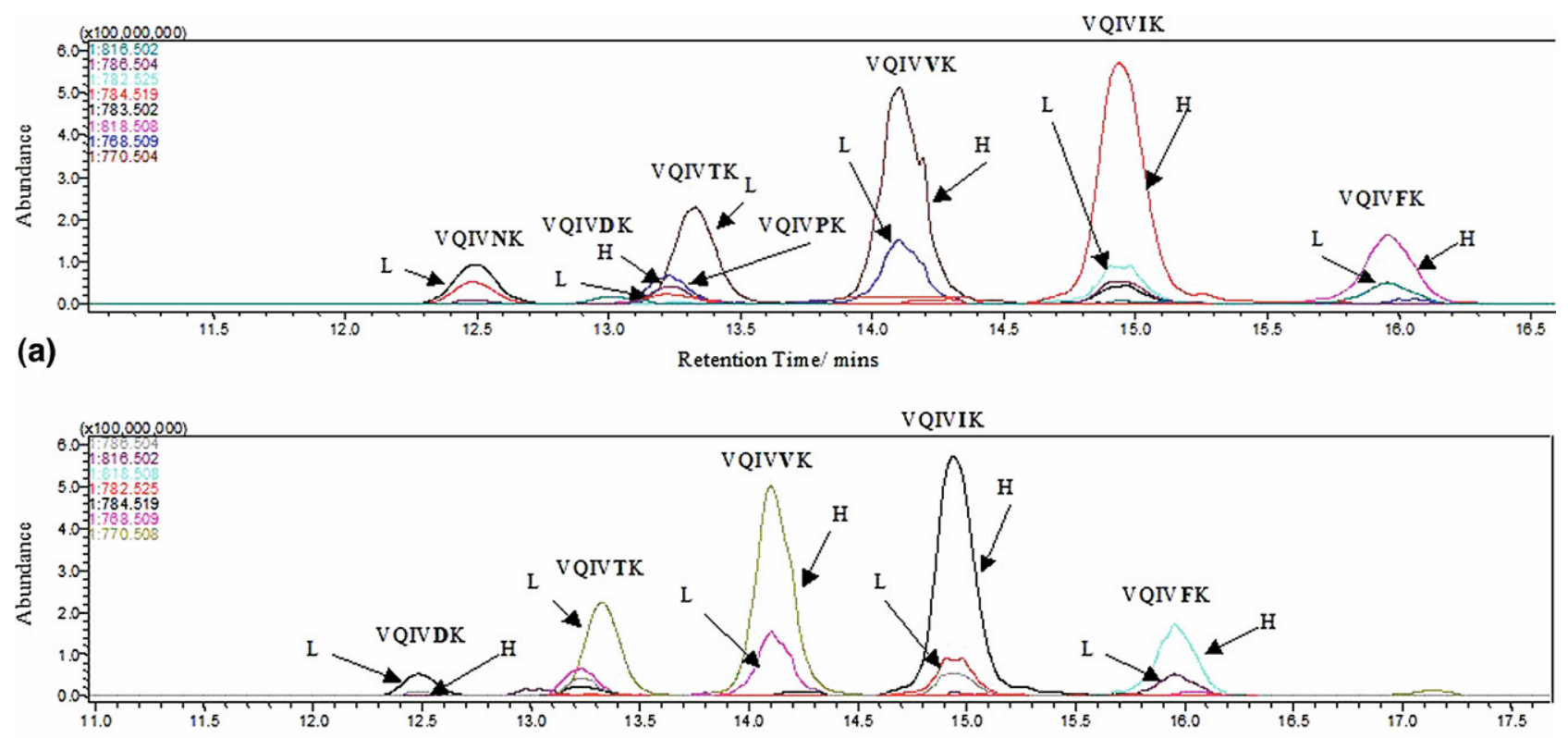

(b)

Retention Time/mins

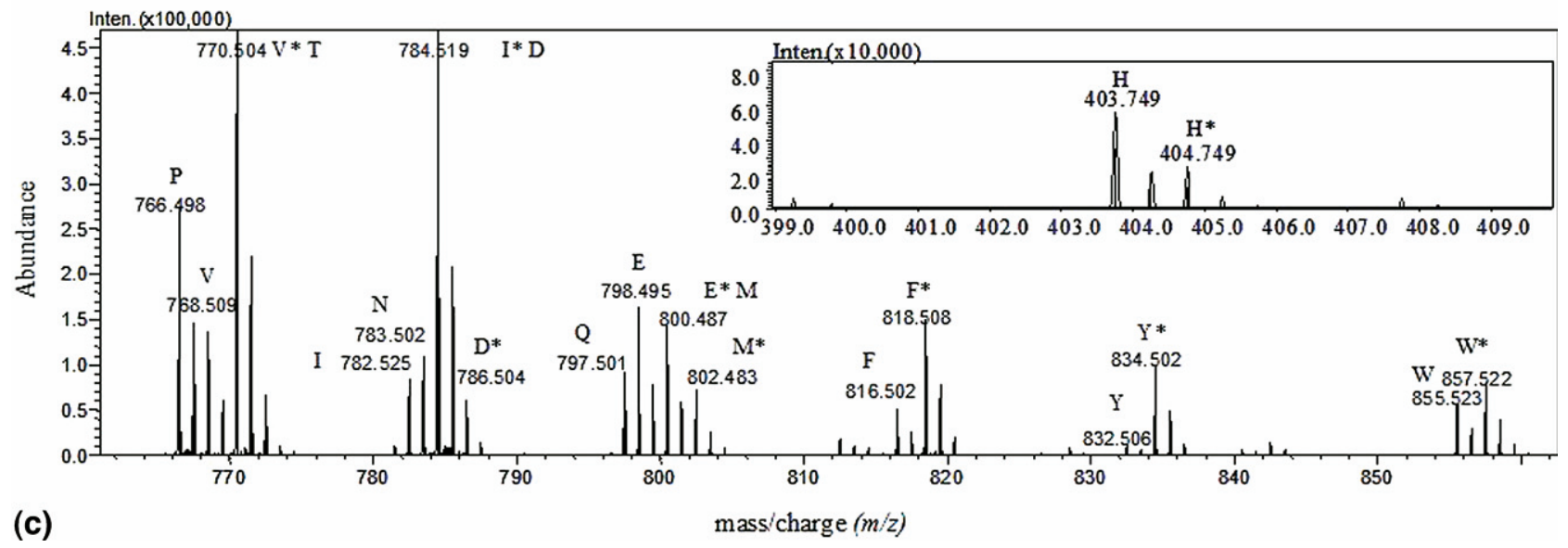

Figure 2. (a) and (b) Extracted ion chromatograms for isotopically derivatized mutated peptides observed in both the supernatant [derivatized with "light" (L) version of OMIU] and as amyloid [derivatized with "heavy" $(\mathrm{H})$ version of OMIU]. (c) Accumulated mass spectrum over the time period of elution (13.7-16.4 $\mathrm{min}$ ) of the mutated peptides that were observed in both phases (b and $\mathbf{c})$. The substituted amino acid at the point of mutation is indicated in the spectrum, where the $*$ identifies the peptide derivatized with the "heavy" version of OMIU. The inset displays both differentially labeled doubly charged species for the histidine-containing analogue.

the ion trap. During ion introduction no RF potential is applied to the ion trap. Once trapped the ions are cooled using argon from a pulse valve. The ToF mass analyzer was used to acquire data in both MS and MSMS modes of operation. In MS mode a $50 \mathrm{~ms}$ ion accumulation time was used before ion trapping. Ions are cooled for $20 \mathrm{~ms}$ before ion ejection into the ToF mass analyzer. Before MSMS analysis precursor ions can be isolated using the filtered noise field (FNF) method, which generates a notched broadband signal composed of frequency components. The FNF is applied to the electrodes of the ion trap, causing the resonant ejection of all unwanted ions. In MSMS mode the ion accumulation time corresponds to $100 \mathrm{~ms}$. The window used for precursor ion isolation corresponds to a width of 3 Th and precursor ion isolation time of $50 \mathrm{~ms}$. To induce fragmentation of the precursor ion, resonant excitation is induced by the application of a supplementary AC potential to the end-cap electrodes. For collision-induced dissociation (CID), argon is used as a collision gas. CID was carried out over $30 \mathrm{~ms}$ and using a $q$ value of $0.251(45 \mathrm{kHz})$. For data-dependent MSMS precursor selection criteria included a charge-state filter selecting only +1 and +2 species and a monoisotopic filter to ensure selection of only the monoisotopic ions for MSMS analysis. Three scans were accumulated in each MSMS spectrum. In both MS and MSMS mode data were acquired over a mass range of 200-2000 Th. In both regimes of operation ions are pulsed into the ToF with an 
Table 1. Theoretical $\mathrm{m} / \mathrm{z}$ corresponding to derivatized mutated peptides

\begin{tabular}{ccll}
\hline Residue change & $m / z$ & Light & Heavy \\
\hline \hline A & 1 & 740.5 & 742.5 \\
D & 1 & 784.49 & 786.49 \\
E & 1 & 798.5 & 800.5 \\
F & 1 & 816.53 & 818.53 \\
G & 1 & 726.48 & 728.48 \\
H & 2 & 403.76 & 404.76 \\
I & 1 & 782.54 & 784.54 \\
K & 2 & 420.28 & 421.28 \\
M & 1 & 800.52 & 802.52 \\
N & 1 & 783.50 & 785.50 \\
P & 1 & 766.51 & 768.51 \\
O & 1 & 797.52 & 799.52 \\
R & 2 & 413.28 & 414.28 \\
S & 1 & 756.49 & 758.49 \\
T & 1 & 770.51 & 772.51 \\
V & 1 & 768.53 & 770.53 \\
W & 1 & 855.54 & 857.54 \\
Y & 1 & 832.52 & 834.52 \\
\hline
\end{tabular}

$\mathrm{m} / \mathrm{z}$ of observed ions are italicized.

a Both $\mathrm{K}$ derivatized.

accelerating potential of $9 \mathrm{kV}$. The detector voltage is set at $1.65 \mathrm{kV}$.

\section{Results and Discussion}

To generate amyloid, all mutated peptides were added to a solution of $20 \mathrm{mM}$ MOPS containing $0.01 \% \mathrm{NaN}_{3}$ at $\mathrm{pH}$ 7.2. Generally, formation of amyloid is observed over a period of 5 days. After centrifugation the peptides present in the amyloid pellet were treated with a solution containing the "heavy" version of OMIU, whereas those in the supernatant were labeled with the "light" version of OMIU. The two solutions were recombined ${ }^{\circ}$ and $^{\circ}$ subjected ${ }^{\circ} \mathrm{to}^{\circ} \mathrm{an}^{\circ}$ online ${ }^{\circ}$ microcapillary ${ }^{\circ} \mathrm{LC}$ separation before analysis on a hybrid quadrupole ion trap time-of-flight mass spectrometer. As previously described for the MALDI analysis of the unfractionated peptide ${ }^{\circ}$ mixture ${ }^{\circ}[19],{ }^{\circ}$ overlap ${ }^{\circ}$ among ${ }^{\circ}$ ions ${ }^{\circ}$ belonging ${ }^{\circ}$ to peptides differing by a few Daltons leads to difficulties in determining the correct ion abundance ratios. Fractionation of the peptide mixture using offline reversedphase LC in conjunction with automated sample spotting onto a MALDI target plate has proved its utility in discriminating between different species. Starting from these premises, an online fractionation approach was implemented here, thus allowing continuous infusion into ${ }^{\circ}$ the ${ }^{\circ}$ mass $^{\circ}$ spectrometer. ${ }^{\circ}$ Figure $^{\circ} 1 \mathrm{a}^{\circ}$ shows ${ }^{\circ}$ the ${ }^{\circ}$ total ion chromatogram (TIC) resulting from a 20 min gradient ${ }^{\circ} \mathrm{LC}^{\circ}$ separation. $^{\circ} \mathrm{As}^{\circ}$ indicated $^{\circ}$ in $^{\circ}$ Figure $^{\circ} 1 \mathrm{~b},{ }^{\circ}$ all $^{\circ} \mathrm{mu}$ tated peptides were eluted between 10 and $17.5 \mathrm{~min}$. The mass spectrum obtained by accumulating all scans over $^{\circ}$ this $^{\circ}$ time $^{\circ}$ period $^{\circ}$ is ${ }^{\circ}$ displayed $^{\circ}$ in $^{\circ}$ Figure $^{\circ} 2 \mathrm{a}^{\circ}$ and identifies the presence of all singly charged mutated peptide ions. No traces of the unmodified peptides were observed, suggesting that the guanidination went to $^{\circ}$ completion $^{\circ}[15] .{ }^{\circ}$ All $^{\circ}$ singly ${ }^{\circ}$ charged $^{\circ}$ peptide $^{\circ}$ ions deriving from the derivatization with the "light" version of OMIU are present in the spectrum. Only in a few case $^{\circ}$ shown $^{\circ}$ in $^{\circ}$ Table $^{\circ} 1^{\circ}$ is $^{\circ}$ the ${ }^{\circ}$ corresponding ${ }^{\circ}$ heavy isotopomer observed. Interestingly, the majority of the peptide ions were detected as singly charged species with the exception of lysine-, histidine-, and argininecontaining peptides that were observed solely as doubly $^{\circ}$ charged $^{\circ}$ ions $^{\circ}\left(\right.$ Figure $^{\circ}$ 1c)..$^{\circ}$ This $^{\circ}$ behavior $^{\circ}$ may $^{\circ}$ be attributable to the presence of two basic residues on which ${ }^{\circ}$ protonation ${ }^{\circ}$ is ${ }^{\circ}$ ighly ${ }^{\circ}$ favored $^{\circ}[21] . .^{\circ}$ Additionally, it should be noted that in the case of the lysine containing peptide, derivatization with the "light" version of OMIU has occurred on both lysine residues.

Extracted ion chromatograms of the resulting mass spectrometric data identify the retention times of the isotopically derivatized mutated peptides together with their ${ }^{\circ}$ abundances. ${ }^{\circ}$ Figure $^{\circ} 2 a^{\circ}$ and ${ }^{\circ} b^{\circ}$ show ${ }^{\circ}$ the $e^{\circ}$ extracted ion chromatograms for all mutated peptides observed in both $^{\circ}$ the ${ }^{\circ}$ supernatant $^{\circ}$ and ${ }^{\circ}$ the $^{\circ}$ amyloid ${ }^{\circ}$ pellet. ${ }^{\circ}$ Table 2 summarizes the data of the isotopically derivatized mutated peptides that were observed. As it can be seen in ${ }^{\circ}$ Table 3 , ${ }^{\circ}$ peptides ${ }^{\circ}$ containing $^{\circ}$ differing ${ }^{\circ}$ amino $0^{\circ}$ acids ${ }^{\circ}$ at the mutation site have different retention times, thus allowing for the separation of isobaric peptides based on their hydrophobicity properties. Thus, resolution of the "light" version of the tyrosine containing peptide at $\mathrm{m} / \mathrm{z}$ at $770.5 \mathrm{Th}$, from the "heavy" version of the valine-containing peptide that is isobaric, was achieved. Figure $^{\circ} 2 a^{\circ}$ and $^{\circ} b^{\circ}$ also $^{\circ}$ indicate ${ }^{\circ}$ the ${ }^{\circ}$ coelution $^{\circ}$ of ${ }^{\circ}$ both isotopic variants for the observed mutated peptides (valine, isoleucine, phenylalanine, tyrosine, methionine, tryptophan, histidine, glutamic acid, and aspartic acid). Accumulation of the MS data over the time period during which the peptides are eluted leads to the accumulated ${ }^{\circ}$ mass $^{\circ}$ spectrum $^{\circ}\left(\text { Figure }^{\circ} 2 \mathrm{c}\right)^{\circ}$ that ${ }^{\circ}$ clearly identifies the presence of both isotopic variants. Integration of the extracted ion chromatograms for the isotopic variants of a given mutated peptide provides a method of quantification between the soluble and insoluble phases and, in addition, a measure of the partition ${ }^{\circ}$ coefficient. ${ }^{\circ}$ Table ${ }^{\circ} 2^{\circ}$ details $^{\circ}$ the ${ }^{\circ}$ partition ${ }^{\circ}$ coefficients for all mutated peptides observed in the amyloid state.

An additional advantage of the GLaD method consists of discriminating different mutated peptides

Table 2. Partition coefficients for all mutated peptides observed in the amyloid state

\begin{tabular}{lr}
\hline Peptide & L:H \\
\hline \hline VOIVFK & 3.85 \\
VOIVIK & 6.60 \\
VOIVVK & 3.42 \\
VOIVWK & 1.66 \\
VOIVYK & 11.02 \\
VOIVMK & 0.81 \\
VOIVHK & 0.45 \\
VOIVDK & 1.62 \\
VOIVEK & 0.48 \\
\hline
\end{tabular}



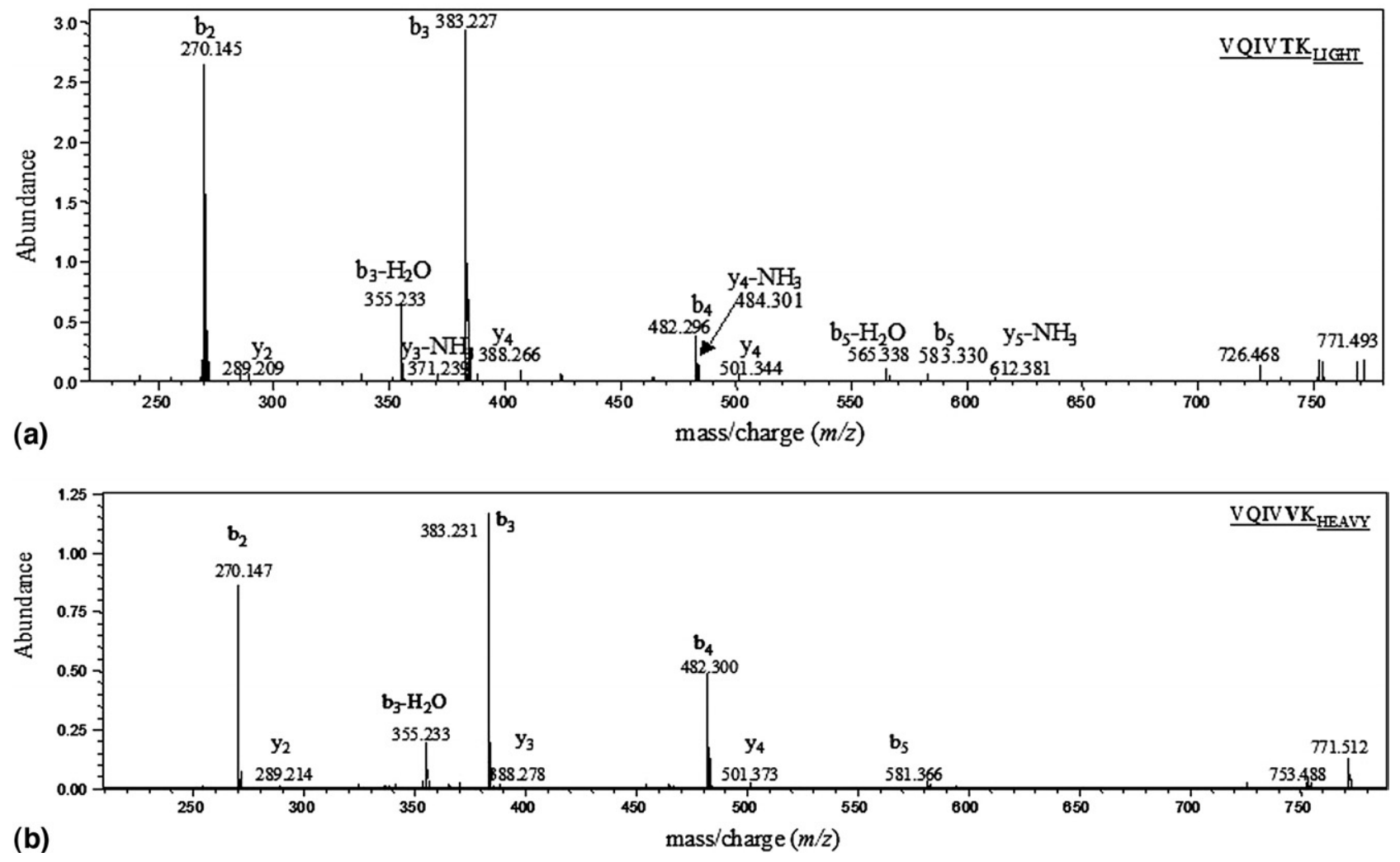

Figure 3. Data-dependent MSMS analysis for: (a) $\mathrm{m} / \mathrm{z} 768.51$, corresponding to the valine-containing peptide derivatized with the "light" version of OMIU; (b) $\mathrm{m} / \mathrm{z} 770.51$, corresponding to the valine-containing peptide derivatized with the "heavy" version of OMIU.

or isotopic variants of a mutated peptide by datadependent ${ }^{\circ} \mathrm{MSMS}^{\circ}$ analysis. ${ }^{\circ}$ Figure $3 \mathrm{a}^{\circ}{ }^{\circ} \mathrm{and}^{\circ} \mathrm{b}^{\circ}$ show ${ }^{\circ}$ the MSMS spectra for data-dependent MSMS analysis of $\mathrm{m} / \mathrm{z} 768.5$ and 770.5 , respectively, corresponding to both isotopic variants of valine-containing peptide. The data clearly indicate that the sequence similarity between the isotopic variants is reflected in the $m / z$ of the b-type ions. However, because the derivatization occurs on the lysine residue at the C-terminus the presence of any y-type ions discriminates between isotopic variants for a mutated peptide precursor ion. Thus, the presence of $\mathrm{y}_{2^{\sigma}} \mathrm{y}_{4^{\circ}}$ ions $^{\circ}$ in $^{\circ}$ Figure ${ }^{\circ} 3 \mathrm{~b}^{\circ}$ of ${ }^{\circ}$ the "heavy" derivatized valine-containing peptide confirms the identity of this ion. In the majority of all data-dependent experiments the MSMS data confirm the ${ }^{\circ}$ identity ${ }^{\circ}$ of $^{\circ}$ the ${ }^{\circ}$ peptide ${ }^{\circ}$ ions. ${ }^{\circ}$ Figure $^{\circ} 4^{\circ}$ shows ${ }^{\circ}$ the MSMS spectra of the "light" derivatized tyrosinecontaining peptide at $m / z 770.5$. This ion is isobaric to the "heavy" derivatized valine-containing peptide displayed ${ }^{\circ}$ in $^{\circ}$ Figure $^{\circ} 3 b .{ }^{\circ}$ Discrimination ${ }^{\circ}$ between ${ }^{\circ}$ the

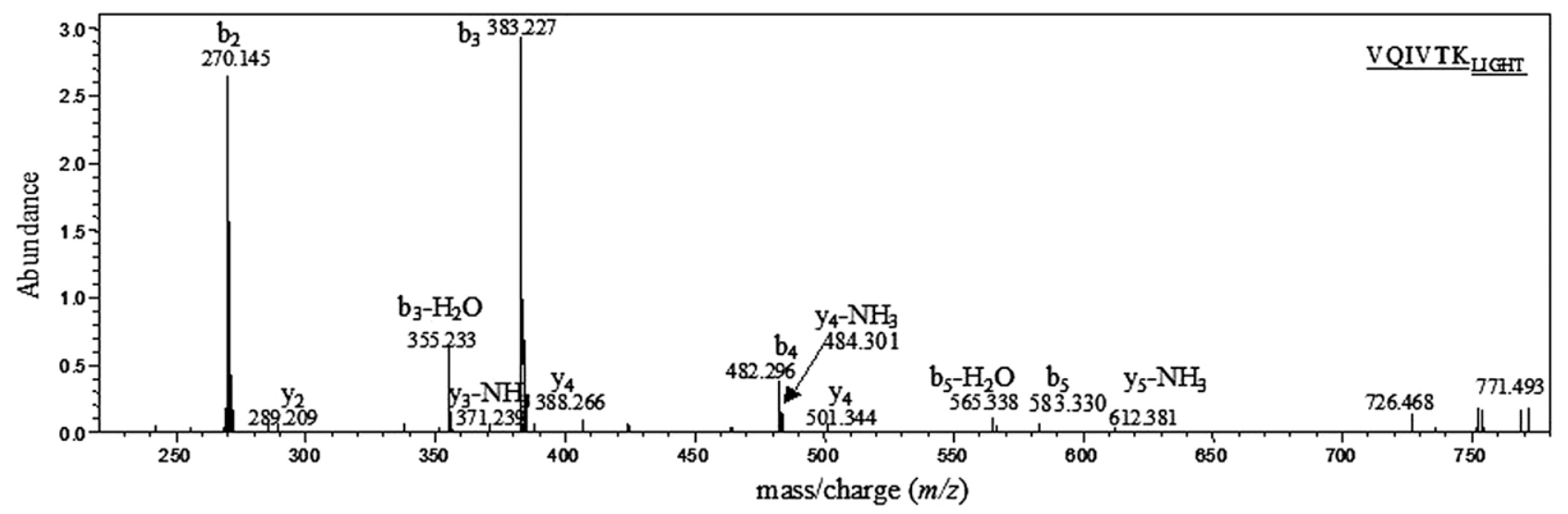

Figure 4. Data-dependent MSMS analysis for $\mathrm{m} / \mathrm{z}$ 770.50, corresponding to the tyrosine-containing peptide derivatized with the "light" version of OMIU. 
Table 3. Reversed-phase LC retention times for mutated peptides. The amino acid at the point of mutation are indicated.

\begin{tabular}{cc}
\hline Substituted amino acid & Retention time (min) \\
\hline \hline His & 10.66 \\
Arg & 10.97 \\
Lys & 11.08 \\
Asn & 12.50 \\
Gln & 12.86 \\
Gly & 12.90 \\
Ser & 12.98 \\
Pro & 13.23 \\
Asp & 13.23 \\
Thr & 13.33 \\
Ala & 13.33 \\
Glu & 13.64 \\
Val & 14.10 \\
Tyr & 14.25 \\
Ile & 14.96 \\
Met & 15.03 \\
Phe & 15.96 \\
Trp & 15.98 \\
\hline
\end{tabular}

two species is achieved by the presence of the $b_{5}$ ion at $m / z 583.330$.

\section{Conclusions}

The use of GLaD in conjunction with online-LC leads to a vast improvement in analysis times. Unlike the offline-LC method implemented in combination with automated sample spotting onto a MALDI target plate, where a large number of sample spots must be analyzed, online-LC electrospray (ES) obliterates this problem because each mutated peptide is eluted directly into the mass spectrometer, thus reducing the analysis time. Contemporaneously, the limit of detection also increases with respect to the LCMALDI experiment [19], the ${ }^{\circ}$ data ${ }^{\circ}$ clearly ${ }^{\circ}$ indicate ${ }^{\circ}$ that ${ }^{\circ}$ formation ${ }^{\circ}$ of amyloid is also observed for the aspartic acid and histidinecontaining peptides. This is explained by the intrinsic nature of the separation process. Whereas in offline LCMALDI the peptides eluted are mixed with the matrix in at least three sample spots, decreasing the amount of analyte present in each individual spot, in online LCMS the peptide eluted is analyzed continuously in the mass spectrometer, increasing the overall sensitivity of analysis. Interestingly, the direct comparison between the ESI and MALDI indicate that the partition coefficients are in accordance, showing minimal variations in response between the two ionization techniques. The critical point in data-dependent LCMSMS tandem analysis is the possibility of performing MSMS on both differentially labeled precursor ions, providing a complementary method for identification and resolution between isobaric species. Together with the relative abundance of both ion pairs, the use of reversed-phase LC in conjunction with ES provides a direct measure of the hydrophobicities of the peptides under investiga- tion. Finally the method presented can be used in principle for quantifying proteins in comparative proteomics-type experiments.

\section{Acknowledgments}

The authors express their thanks to Shimadzu Corporation for funding of this project.

\section{References}

1. Ong, S. E.; Mann, M. Mass-Spectrometry-Based Proteomics Turns Quantitative. Nat. Chem. Biol. 2005, 1, 252-262.

2. Brancia, F. L. Mass Spectrometry Based Strategies in Quantitative Proteomics 151. Curr. Anal. Chem. 2006, 2, 1-7.

3. Pasa, T. L.; Jensen, P. K.; Anderson, D. J.; Lipton, M. S.; Peden, K. K.; Martinovic, S.; Tolic, N.; Bruce, J. E.; Smith, R. D. High Throughput Proteome-Wide Precision Measurements of Protein Expression Using Mass Spectrometry. J. Am. Chem. Soc. 1999, 121, 7949-7950.

4. Veenstra, T. D.; Martinovic, S.; Anderson, G. A.; Pasa-Tolic, L.; Smith, R. D. Proteome Analysis Using Selective Incorporation of Isotopically Labeled Amino Acids. J. Am. Soc. Mass Spectrom. 2000, 11, 78-82.

5. Pratt, J. M.; Robertson, D. H.; Gaskell, S. J.; Riba-Garcia, I.; Hubbard, S. J.; Sidhu, K.; Oliver, S. G.; Butler, P.; Hayes, A.; Petty, J.; Beynon, R. J. Stable Isotope Labelling In Vivo as an Aid to Protein Identification in Peptide Mass Fingerprinting. Proteomics 2002, 2, 157-163.

6. Ong, S. E.; Blagoev, B.; Kratchmarova, I.; Kristensen, D. B.; Steen, H. Pandey, A.; Mann, M. Stable Isotope Labeling by Amino Acids in Cell Culture, SILAC, as a Simple and Accurate Approach to Expression Proteomics. Mol. Cell. Proteomics 2002, 1, 376-386.

7. Ong, S. E.; Kratchmarova, I.; Mann, M. Properties of 13C-Substituted Arginine in Stable Isotope Labeling by Amino Acids in Cell Culture (SILAC) 1. J. Proteome Res. 2003, 2, 173-181.

8. Gygi, S. P.; Rist, B.; Gerber, S. A.; Turecek, F.; Gelb, M. H.; Aebersold, R Quantitative Analysis of Complex Protein Mixtures Using IsotopeCoded Affinity Tags. Nat. Biotechnol. 1999, 17, 994-999.

9. Li, J.; Steen, H.; Gygi, S. P. Protein Profiling with Cleavable Isotope Coded Affinity Tag (cICAT) Reagents: The Yeast Salinity Stress Response. Mol. Cell Proteomics 2003, 2, 1198-1204.

10. Goodlett, D. R.; Keller, A.; Watts, J. D.; Newitt, R.; Yi, E. C.; Purvine, S.; Eng, J. K.; von Haller, P.; Aebersold, R.; Kolker, E. Differential Stable Isotope Labeling of Peptides for Quantitation and De Novo Sequence Derivation. Rapid Commun. Mass Spectrom. 2001, 15, 1214-1221.

11. Munchbach, M.; Quadroni, M.; Miotto, G.; James, P. Quantitation and Facilitated De Novo Sequencing of Proteins by Isotopic N-Terminal Labeling of Peptides with a Fragmentation-Directing Moiety. Anal. Chem. 2000, 72, 4047-4057.

12. Chakraborty, A.; Regnier, F. E. Global Internal Standard Technology for Comparative Proteomics. J. Chromatogr. A 2002, 949, 173-184.

13. Liu, P.; Regnier, F. E. An Isotope Coding Strategy for Proteomics Involving Both Amine and Carboxyl Group Labeling 1. J. Prot. Res. 2002, 1, 443-450.

14. Brancia, F. L.; Oliver, S. G.; Gaskell, S. J. Improved Matrix-Assisted Laser Desorption/Ionization Mass Spectrometric Analysis of Tryptic Hydrolysates of Proteins Following Guanidination of Lysine-Containing Peptides. Rapid Commun. Mass Spectrom. 2000, 14, 2070-2073.

15. Brancia, F. L.; Openshaw, M. E.; Kumashiro, S. Investigation of the Electrospray Response of Lysine-, Arginine-, and Homoarginine-Terminal Peptide Mixtures by Liquid Chromatography/Mass Spectrometry 1. Rapid Commun. Mass Spectrom. 2002, 16, 2255-2259.

16. Beardsley, R. L.; Karty, J. A.; Reilly, J. P. Enhancing the Intensities of Lysine-Terminated Tryptic Peptide Ions in Matrix-Assisted Laser Desorption/Ionization Mass Spectrometry. Rapid Commun. Mass Spectrom. 2000, 14, 2147-2153.

17. Beardsley, R. L.; Reilly, J. P. Optimization of Guanidination Procedures for MALDI Mass Mapping. Anal. Chem. 2002, 74, 1884-1890.

18. Brancia, F. L.; Montgomery, H.; Tanaka, K.; Kumashiro, S. Guanidino Labeling Derivatization Strategy for Global Characterization of Peptide Mixtures by Liquid Chromatography Matrix-Assisted Laser Desorption/Ionization Mass Spectrometry. Anal. Chem. 2004, 76, 2748-2755.

19. Rojas Quijano, F. A.; Morrow, D.; Wise, B. M.; Brancia, F. L.; Goux, W. J. Prediction of Nucleating Sequences from Amyloidogenic Propensities of Tau-Related Peptides. Biochemistry 2006, 45, 4638-4652.

20. Goux, W. J.; Kopplin, L.; Nguyen, A. D.; Leak, K.; Rutkofsky, M.; Shanmuganandam, V. D.; Sharma, D.; Inouye, H.; Kirschner, D. A. The Formation of Straight and Twisted Filaments from Short Tau Peptides. J. Biol. Chem. 2004, 279, 26868-26875.

21. Burlet, O.; Orkiszewski, R. S.; Ballard, K. D.; Gaskell, S. J. Charge Promotion of Low-Energy Fragmentations of Peptide Ions. Rapid Commun. Mass Spectrom. 1992, 6, 658-662. 